\title{
Behaviour of chlorine 36 in cultivated terrestrial ecosystems
}

\author{
C. Colle, S. Mauger, C. Massiani ${ }^{1}$, V.A. Kashparov ${ }^{2}$ and G. Grasset \\ Institute of Protection and Nuclear Safety, DPRE/SERLAB, \\ Laboratory of Experimental Radioecology, Cadarache, bâtiment 180 , \\ BP. 1, 13108 Saint-Paul-lez-Durance cedex, France \\ 'Laboratoire de Chimie de l'Environnement, Université d'Aix-Marseille l, France \\ ${ }^{2}$ Ukrainian Institute of Agricultural Radiology, UIAR, Kiev, Ukraine
}

\begin{abstract}
The retention of chlorine 36 by soils is studied. Batch investigations are performed to determine distribution coefficient values for various types of soils with physico-chemical properties covering a wide range of pH, organic matter and sesquioxydes content. The soil /soil solution distribution coefficient values are very weak and seem to be mainly conditioned by the organic carbon and the sesquiox ydes content of the soi].

Root uptake of chlorine 36 in some vegetables is also determined for root-vegetable (radish), a leafy-vegetabie (lettuce) and a fruit-vegetable (bean) are experimented. Cultures are made on three types of soil with contrasted properties : "acidic", "calcareous" and " organic". The values of the soil/plant concentration ratios expressed with regard to the dry weight of vegetables are very high ; they vary between 18 and 377 according to the organ of the plant and the soil type. The strongest ${ }^{36} \mathrm{Cl}$ root uptake value is obtained with the calcareous soil and the lowest one on the organic one.
\end{abstract}

\section{INTRODUCTEON}

Chlorine-36 is a radionuclide produced in the core of nuclear reactors by neutron activation of stable chlorine contained in impurities in the unirradiated fuel [3]. It can be discharged into the environment during the recycling of spent nuclear fuel and from nuclear waste disposal. Whereas it is well known that chlorine is a biologically important element with a high degree of mobility in the terrestrial food chains, the behaviour of the long half-life radioisotope ${ }^{36} \mathrm{Cl}(300,000$ years) is poorly documented. Radioecological parameters are needed for assessment models to estimate ${ }^{36} \mathrm{Cl}$ impact on the human health and the natural environment [4]. In this aim, batch experiments have been performed to provide soil-solution distribution coefficients (Kd) for several types of soils. The results show that Kd are insignificant for all the soils, exccpt for the tropical organic one which has a very high organic matter content $(34.2 \%)$, a low $\mathrm{pH}$, important rates of active-Fe and active-Al. Some investigations on the soil to plant transfer of chlorine from pots experiments are reported. They are performed with to three types of soil (" acidic", "calcareous", "organic ") and three types of crops : radishes, lettuces, beans.

\section{MATERIALS AND METHODS}

\subsection{Batch experiments}

\subsubsection{Physico-chemical characteristics of the soils}

Samples from superficial horizon of sixteen types of french soils (soils $n^{\circ} l$ to 16) and one soil from a tropical country (soil $\left.n^{\circ} 17\right)$ were tested. They were analysed for $\mathrm{pH}\left(\mathrm{H}_{2} \mathrm{O}\right)$, cation exchange capacity (CEC), organic matter, active iron, active aluminium. watersoluble stable chlorine, texture. These main physico-chemical characteristics are summarized in Table 1. They show contrasting properties especially for $\mathrm{pH}$, organic matter content, active iron and active aluminium, more particularly concerning the tropical organic soil $\left(n^{\circ} 17\right)$. 
Table 1: Main physico-chemical characteristics of the soils

\begin{tabular}{|c|c|c|c|c|c|c|l|}
\hline Soil $\mathrm{n}^{\circ}$ & $\begin{array}{c}\mathbf{p H} \\
\left(\mathbf{H}_{2} \mathrm{O}\right)\end{array}$ & $\begin{array}{c}\text { CEC } \\
\left(\mathrm{meq} \mathrm{kg}^{\prime}\right)\end{array}$ & $\begin{array}{c}\text { Organic } \\
\text { matter } \\
\left(\mathrm{g} \mathrm{kg}^{-1}\right)\end{array}$ & $\begin{array}{c}\text { Watersoluble stable Cl } \\
\left(\mathrm{mg} \mathrm{kg}^{-1}\right)\end{array}$ & $\begin{array}{c}\text { Active-Fe } \\
\left(\mathrm{mg} \mathrm{kg}^{-1}\right)\end{array}$ & $\begin{array}{c}\text { Active-Al } \\
\left(\mathrm{mg} \mathrm{kg}^{-1}\right)\end{array}$ & \multicolumn{1}{|c|}{ Texture } \\
\hline 1 & 8.4 & 56 & 37 & 18 & 10.0 & - & Loamy-sand \\
\hline 2 & 5.6 & 107 & 71 & 27 & 13.0 & 1.1 & Sandy \\
\hline 3 & 4.2 & 61 & 45 & 29 & 1.6 & - & Sandy-loam \\
\hline 4 & 7.4 & 218 & 34 & 18 & 20.3 & 1.3 & Loamy \\
\hline 5 & 4.5 & 156 & 87 & 20 & 6.1 & 0.6 & Loamy-sand \\
\hline 6 & 8.1 & 213 & 57 & 38 & 3.0 & - & Loamy-clay \\
\hline 7 & 5.1 & 174 & 72 & 30 & 11.8 & 0.6 & Loamy-clay \\
\hline 8 & 7.6 & 209 & 119 & 21 & 17.8 & 0.6 & Loamy-clay \\
\hline 9 & 5.4 & 153 & 80 & 25 & 11.6 & 1.0 & Loamy-clay \\
\hline 10 & 7.2 & 269 & 95 & 100 & 41.3 & - & Laamy-clay \\
\hline 11 & 5.5 & 141 & 49 & 13 & 5.7 & 1.3 & sandy \\
\hline 12 & 4.3 & 160 & 98 & 32 & 4.3 & 1.8 & Loamy-clay \\
\hline 13 & 6.4 & 73 & 18 & 25 & 2.6 & 1.2 & sandy \\
\hline 14 & 6.0 & 144 & 54 & 7 & 1.6 & 2.0 & clay \\
\hline 15 & 8.0 & 160 & 66 & 19 & 2.1 & 0.4 & loam \\
\hline 16 & 6.8 & 97 & 35 & 57 & 1.3 & 0.2 & Sandy-loam \\
\hline 17 & 4.1 & 28 & 342 & 35 & 679.0 & 258.0 & Loamy-clay \\
\hline
\end{tabular}

\subsubsection{Experimental procedure}

Two grams of each sieved (through a $2 \mathrm{~mm}$ mesh screen) and air dried soil sample were weighed in a polyethylene bottle. Twenty milliliters of distilled water containing radiochlorine tracer $\left({ }^{36} \mathrm{Cl}\right.$ as sodium chloride) were added and the bottles were shaken with a mechanical shaker at room temperature. Preliminary tests using different shaking time (1,2, 4, 7, 17 and 30 days $)$ indicated that the sorption equilibrium was always reached after one day. For this reason a shaking time of 2 days was used for all batch experiments. Then, the mixture was centrifugated at $3600 \mathrm{rpm}$ for 15 minutes. A one milliliter aliquot of the supernatant was removed, mixed with $19 \mathrm{ml}$ of a scintillation cocktail (Instagel Plus Packard) and measured for ${ }^{36} \mathrm{Cl}$ activity using a liquid scintillation counter (Quantulus Wallac). Seven replicates were performed for each soil. The counting emors were about $5 \%$.

On the basis of the obtained Kd values, additional investigations were performed on the soil which had sorbed the higher amount of chlorine : the Kd measurements were performed with different initial activities of the nuclide in the contaminating solution in order to determine the shape of the sorption isotherm. Five concentrations, varying by up to four orders of magnitude, were used : $1.2,12,112,940$ and $9450 \mathrm{~Bq} \mathrm{ml}^{-1}$.

\subsection{Soil to plant transfer experiments}

Three soils, taken among those tested for batch experiments ( ${ }^{\circ}$ !: "caicareous" soil, $\mathrm{n}^{\circ} 2$ : "acidic" soil and $n^{\circ} 17$ : "organic" tropical soil described in Table 1), were fitted into polyethylene pots (dianeter : $16 \mathrm{~cm}$, depth : $20 \mathrm{~cm}$ ) by successive thin layers $(1 \mathrm{~cm})$. Each layer was moistened by distilled water and then uniformly sprayed with the contaminating solution : the final ${ }^{36} \mathrm{Cl}$ contents in soils are reported in Table 2. All pots were placed in a greenhouse under controlled conditions and kept wet until planting. 
Table 2: Mass and specific activity of soils used in soil to plant transfer experiment.

\begin{tabular}{l|cc}
\hline \multicolumn{1}{c|}{ Soil } & Soil weight (kg dry soil) & Soil activity (Bq kg.' dry soil) \\
\hline "Calcareous" & 6.5 & 234000 \\
"Acidic" & 5.8 & 203000 \\
"organic" tropical & 4.7 & 222500 \\
\hline
\end{tabular}

The plants were sown one month after the soil contamination. Five replicates were made for each soil and plant type. Three kinds of vegetables were cultivated : beans, lettuces and radishes. The pots were watered with distilled water two to three times a week, in small quantities in order to prevent leaching losses of chlorine from the potted soils. At harvest the plants were divided into organs parts : stems, leaves and pods for beans, leaves for lettuce, leaves and roots for radishes. After oven drying at $60^{\circ} \mathrm{C}$ until reaching a constant weight, the samples were solubilized with nitric acid $\left(\mathrm{HNO}_{3} 65 \%\right)$ and hydrogen peroxyde in a distillation flask. Vapours were condensed and trapped in a sodium hydroxide solution $(0,1 \mathrm{~N})$. The solutions were measured for ${ }^{36} \mathrm{Cl}$ activity.

\section{RESULTS AND DISCUSSION}

\subsection{Soil adsorption experiments}

The sorption percentage and the distribution coefficient $(\mathrm{Kd})$ were calculated according to the following expressions:

$$
\begin{aligned}
& \text { Sorption percentage (\%) }=\frac{A_{i}-A_{f}}{A_{i}} \times 100, \\
& \mathrm{~K}_{\mathrm{d}}\left(1 \mathrm{~kg}^{-1}\right)=\frac{\left(A_{i}-A_{f}\right) \times V}{A_{f} \times M}
\end{aligned}
$$

where $A_{1}$ is the initial concentration ( $\mathrm{Bq} \mathrm{I}^{-1}$ ) of ${ }^{36} \mathrm{Cl}$ in the contaminating solution, $A_{f}$ the concentration (Bq $\left.\Gamma^{i}\right)$ of ${ }^{36} \mathrm{Cl}$ in the supernatant solution after contact with the soil, $V$ the solution volume (I) and $M$ the dry soil weight $(\mathrm{kg})$.

The $\mathrm{Kd}$ and sorption percentages determined for all the soils, are not significantly different from zero, except for the soil number 8 (sorption percentage $=2.4 \% ; \mathrm{Kd}=0.12 \mathrm{I} \mathrm{kg}^{-1}$ ) and the tropical organic one $\left(n^{\circ}\right.$ 17). The values measured for this soil are given in Table 3 . These results indicate that the retention of chlorine is low and that the sorption equilibrium between the soil and the contaminating solution was readily reached : the Kd became constant after few hours. This phenomenon could be explained in term of sorption onto sesquioxides in connection with the low $\mathrm{pH}$, the very high active-Fe and actice-Al content of this soil. Sesquioxydes show an increasing capacity for anions binding with decreasing $\mathrm{pH}$. In one hand this behaviour would be similar to the iodine one in very acidic soils [5], [6]. On the other hand the organic matter appears to be less important for chlorine than for iodine in the mechanisms of retention by calcareous soils. 
Table 3 : Distribution coefficients (Kd) and sorption percentage of the tropical organic soil as a fonction of contact time between the soil and the contaminating solution.

\begin{tabular}{|lccccc|}
\hline \multicolumn{5}{c|}{ Contact time (hours) } \\
\hline & 5 & 24 & 48 & 96 & 168 \\
Kd $\left(1 \mathrm{~kg}^{-1}\right)$ & $1.2 \pm 0.2$ & $1.2 \pm 0.1$ & $1.2 \pm 0.1$ & $1.3 \pm 0.2$ & $1.1 \pm 1.1$ \\
Sorption percentage & $10.4 \pm 1.5$ & $10.9 \pm 0.5$ & $10.8 \pm 0.8$ & $11.6 \pm 1.2$ & $10.1 \pm 0.5$ \\
\hline
\end{tabular}

As can be seen on Figure 1 the distribution coefficient is independent of the concentration of the radionuclide in the contaminating solution. Indeed there is a strong correlation between the activity bound to the soil and the activity in solution $\left(r^{2}>0.99\right)$ testifying of important degree of linear dependence of the sorption isotherm within the range of the radionuclide concentration used (four orders of magnitude).

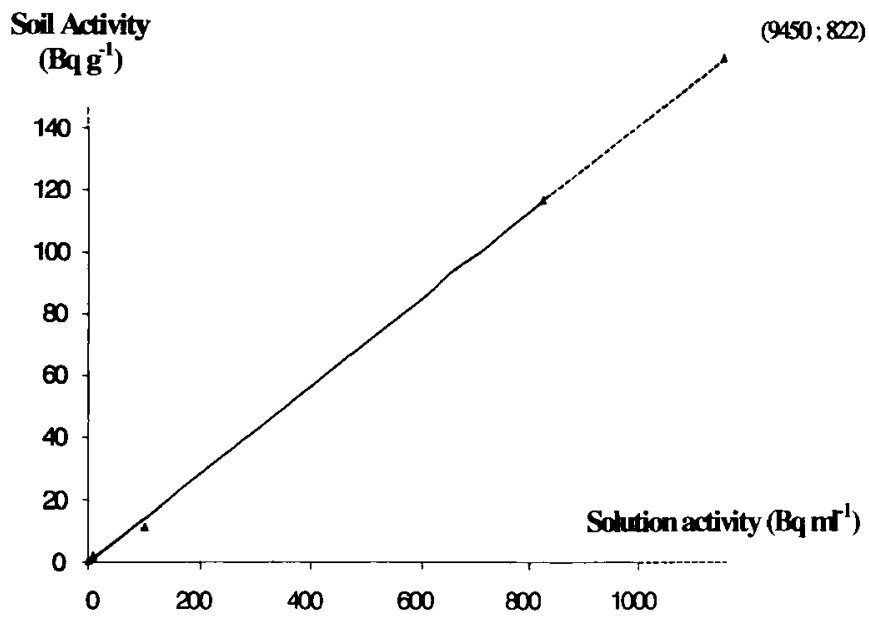

Figure 1: Sorption isotherm of ${ }^{36} \mathrm{Cl}$ by the tropical organic soil 


\subsection{Root uptake of ${ }^{36} \mathrm{Cl}$ by vegetation}

The soilplant concentration ratio is defined as the content of the nuclide per unit weight of the plant organ at the time of harvest $\left(\mathrm{Bq} \mathrm{kg}^{-1}\right.$ ) divided by the concentration of the nuclide per unit weight of dry soil (Bq $\mathrm{kg}^{-1}$ ). The calculations of the concentration ratios are made on a wet and on a dry weight basis for the plants. They are listed in Table 4 as mean values of measurements on five samples.

Tableau 4 : Concentration ratios (CR) of ${ }^{36} \mathrm{Cl}$ from the three types of soils and various organs of beans, lettuces and radishes.

\begin{tabular}{|c|c|c|c|c|}
\hline Soil type & Vegetables & Plant organ & $\begin{array}{c}\text { CR } \\
\text { (Bq kg ' wet plant/Bq kg } \\
\text { dry soil) }\end{array}$ & $\begin{array}{c}\text { CR } \\
\begin{array}{c}\text { (Bq kg } \mathbf{k g}^{-1} \text { dry plant/Bq kg } \\
\text { dry soil) }\end{array}\end{array}$ \\
\hline \multirow[t]{3}{*}{ "Calcareous" } & Bean & $\begin{array}{l}\text { Leaves } \\
\text { Stems } \\
\text { Pods }\end{array}$ & $\begin{array}{c}60 \\
27 \\
9 \\
\end{array}$ & $\begin{array}{l}377 \\
165 \\
118 \\
\end{array}$ \\
\hline & Lettuce & Leaves & 18 & 226 \\
\hline & Radish & $\begin{array}{l}\text { Leaves } \\
\text { Roots }\end{array}$ & $\begin{array}{c}19 \\
5\end{array}$ & $\begin{array}{c}184 \\
68\end{array}$ \\
\hline \multirow[t]{3}{*}{$"$ Acidic" } & Bean & $\begin{array}{l}\text { Leaves } \\
\text { Stems } \\
\text { Pods }\end{array}$ & $\begin{array}{c}16 \\
9 \\
2\end{array}$ & $\begin{array}{l}105 \\
48 \\
25\end{array}$ \\
\hline & Lettuce & Leaves & 6 & 103 \\
\hline & Radish & $\begin{array}{l}\text { Leaves } \\
\text { Roots }\end{array}$ & $\begin{array}{c}10 \\
5\end{array}$ & $\begin{array}{l}95 \\
51\end{array}$ \\
\hline \multirow[t]{3}{*}{ "Organic" } & Bean & $\begin{array}{l}\text { Leaves } \\
\text { Stens } \\
\text { Pods }\end{array}$ & $\begin{array}{l}8 \\
5 \\
2 \\
\end{array}$ & $\begin{array}{l}43 \\
37 \\
18 \\
\end{array}$ \\
\hline & Lettuce & Leaves & 5 & 82 \\
\hline & Radish & $\begin{array}{l}\text { Leaves } \\
\text { Roots }\end{array}$ & $\begin{array}{l}9 \\
4 \\
\end{array}$ & $\begin{array}{l}89 \\
37 \\
\end{array}$ \\
\hline
\end{tabular}

The soil/plant concentration ratios, expressed on a dry weight basis, are in the range of 18 to 377 . They indicate that chlorine uptake by plants is considerable and belongs to the "strongly concentrated" group of elements. These experimental results are in good agreement with estimates and most of the available data reported in studies on the effects of salt-stress in soils polluted with sodium chloride [1], [2].

Furthermore the soil to plant transfer of chlorine appears to be markedly affected by soil properties. The highest uptake occurs from "calcareous" soil similarly to others anionic elements in soils. The lowest soil to plant transfer observed from the "organic" soil is consistant with the Kd value obtained with this soil.

The root-adsorbed chlorine is translocated in a more extend towards the leaves and stems, then roots and fruits. Furthermore, the concentration ratios measured show that chlorine is very mobile in plants.

\section{CONCLUSION}

Chlorine-36 has to be considered as an important radionuclide in radioecology, because of its long half-life, its high mobility in soil and its very important bioavailability for plants. On the basis of the data obtained from the experimental investigations described in this paper the uptake of chlorinc-36 by plants from soil is among the highest of any radionuclide. The problem of chlorine availability to biota will require further investigations to determine which processes control the sorption and chemical fate in plants. Researches 
have to be focussed on the mechanisms governing chlorine retention by soils, particularly in relation with the organic matter in alkaline soils and the sesquioxides of iron and aluminium in acidic conditions.

\section{Acknowledgments}

The authors are grateful to $\mathrm{P}$. Hurtevent for his technical collaboration and to $\mathrm{M}$. Morello for radioactive measurements.

\section{REFERENCES}

[1] Ashton J. and Sumerling T.J. Biosphere database for assessments of radioactive waste disposals. DOE report $n^{\circ} \mathrm{DOE} / \mathrm{RW} / 88.083$. (1988)

[2] Coughtrey P.J., Jackson D., Thome M.C. Radionuclide distribution and transport in terrestrial and aquatic ecosystems 3. (AA Balkema publ, Rotterdam, 1983) pp. 77-101

[3] Sheppard, S. C., Johnson L. H., Goodwin B.W., Tait J. C., Wuschke D.M., Davison C.C., Waste Management 16(7) (1996) 607-614.

[4] Sheppard, S. C., Evenden W. G., Macdonald C.R., Joumal of Environmental Radioactivity 43 (1999) 65-76.

[5] Whitehead D.C. J. Sci. Food Agric. 25 (1974) 73-79

[6] Whitehead D.C. Journal of Soil Science. 25(4) (1974) $461-470$ 